\title{
Ammonium Alleviates Redox State in Solanum Seedlings under Cadmium Stress Conditions
}

\author{
Afef Nasraoui-Hajaji ${ }^{1 *}$, Houda Gouia ${ }^{1}$, Elisa Carrayol ${ }^{2}$ and Chiraz Haouari-Chaffei ${ }^{1}$
}

${ }^{1}$ Unité de Recherche, Nutrition et Métabolisme Azotés et Protéines de Stress, Université de Tunis El-Manar, Faculté des sciences de Tunis, Département de Biologie, Campus universitaire, 1060 Tunis, Tunisie

${ }^{2}$ Unité de nutrition azotée des plantes, INRA, route de Saint-Cyr, F-78027 Versailles, France

\begin{abstract}
Cadmium effects on growth and oxidative stress were investigated in 21-day-old tomato seedlings (Solanum) grown in hydroponics media containing $5 \mathrm{mM}$ of $\mathrm{KNO}_{3}$ or $(\mathrm{NH} 4)_{2} \mathrm{SO}_{4}$ and three Cd levels as $\mathrm{CdCl}_{2}(0,5$ and 25 $\mu \mathrm{M})$ for $14 \mathrm{~d}$. Cadmium was more accumulated in nitrate-fed tomato compared to ammonium-fed ones. Dry weight, Chla, Chlb and carotenoides contents were reduced in $\mathrm{NO}_{3}^{-}$-fed tomato. But in $\mathrm{NH}_{4}^{+}$-fed plants the parameters were increased. Cadmium induced an increase in the $\mathrm{H}_{2} \mathrm{O}_{2}$ and MDA levels which was more pronounced in nitrate-fed tomato. Antioxidant enzyme activities such as superoxide dismutase (SOD), catalase (CAT), and ascorbate peroxidase (APX) were induced with Cd. But, the enhancement degree of these enzymes activities were higher in ammonium-fed tomato compared to those grown with nitrate. These data suggested that antioxidative activity developed by tomato leaves is more induced by cadmium when ammonium was added in nutrient solution as nitrogen source. This can be related to the ability of cadmium to induce an accumulation of reactive oxygen species (ROS) less pronounced in presence of ammonium regime. The beneficial effect of $\mathrm{NH}_{4}^{+}$on $\mathrm{Cd}$ toxicity was confirmed by a significant decrease in MDA level and accumulation of photosynthetic pigments.
\end{abstract}

Keywords: Antioxidant enzymes; Nitrogen; Tomato; Cadmium; Lipid peroxidation

Abbreviations: APX: Ascorbate Peroxidase; CAT: Catalase; $\mathrm{H}_{2} \mathrm{O}_{2}$ : Hydrogen Peroxide; MDA: Malondialdehyde; NBT: Nitro Blue Tetrazolium; ROS: Reactive Oxygen Species; SOD: Superoxide Dismutase

\section{Introduction}

Cadmium (Cd) is one of the most important metals in terms of food-chain contamination, because it is readily taken up by the cells of different plant species [1,2]. In plants, $\mathrm{Cd}$ is known to disturb growth, amino-acid biosynthesis [3], nitrogen metabolism [4,5] and photosynthesis [6,7]. Plants face constant risk from reactive oxygen species (ROS), which are inevitably generated as products of photosynthesis and other cellular metabolic processes [8]. In plants, ROS are produced continuously as byproducts of various metabolic pathways that are localized in different cellular compartments [9], but under stressful conditions, their formation might be in excess of antioxidant scavenging capacity, thus creating oxidative stress by reaction and damage to all biomolecules, especially proteins, due to the higher rate constants of the reaction of the superoxide anion with amino acid side chains [10]. In addition, one of the most damaging effects of oxygen cytotoxic species and their products in cells is the peroxidation of membrane lipids [9]. High ROS levels can damage proteins and DNA [11]. Thus, plants need to earnestly control ROS overall levels by the co-ordinated action of several antioxidant enzymes such as superoxide dismutase (SOD, E.C. 1.15.1.1), catalase (CAT, E.C. 1.11.1.6), ascorbate peroxidase (APX, E.C. 1.11.1.11), and glutathione reductase (GR; EC 1.6.4.2). Superoxide dismutase is the major superoxide radical scavenger and its enzymatic action results in $\mathrm{H}_{2} \mathrm{O}_{2}$ and $\mathrm{O}_{2}$ formation. The product of SOD activity $\left(\mathrm{H}_{2} \mathrm{O}_{2}\right)$ is still toxic and must be eliminated by conversion to $\mathrm{H}_{2} \mathrm{O}$ in subsequent reactions. CAT and several classes of peroxidases like APX then scavenge the $\mathrm{H}_{2} \mathrm{O}_{2}$ produced $[9,12]$. Inorganic nitrogen uptake into plant roots is under strict control in accordance with the nitrogen demand of the plant. Generally, plants prefers nitrate as nitrogen source. But, every other plant species grown in paddy fields predominantly utilizes ammonium during most of the growing period, since ammonium is the major form of inorganic nitrogen in hypoxic and anaerobic soils [13]. However, excessive ammonium uptake into plants can lead to toxic effects $[5,14]$.

Among literature, oxidative stress is studied depending on the type of stress without return look at the form of nitrogen used. Since in nature, plants are in front of the various factors influencing his life. Study of antioxidative enzymes activity in plants cultivated in presence of different nitrogen forms and exposed to heavy metal might be for a great importance. In fact, today, environment pollution by heavy metals is a growing concern in the research community, since it may enter the environment through drainage water, river canal systems carrying industrial and different agricultural practices. Over that, ammonium nutrition is a widespread regime in the different ecosystems.

In the present research we essay to evidence that ammonium alleviates cadmium induced-oxidative stress in tomato leaves. In the same conditions, activities of antioxidant enzymes, which can be implicated in the oxidative stress defense, were measured.

\section{Materials and Methods}

\section{Plant material}

Seeds of the tomato (Solanum lycopersicon) were germinated in petri dishes in the dark. Seedlings were transferred and grown under

*Corresponding author: Afef Nasraoui-Hajaji, Unité de Recherche, Nutrition et Métabolisme Azotés et Protéines de Stress, Université de Tunis El-Manar, Faculté des sciences de Tunis, Département de Biologie, Campus, E-mail: hajajiafef@yahoo.fr

Received April 20, 2012; Accepted May 10, 2012; Published May 12, 2012

Citation: Nasraoui-Hajaji A, Gouia H, Carrayol E, Haouari-Chaffei C (2012) Ammonium Alleviates Redox State in Solanum Seedlings under Cadmium Stress Conditions. J Environ Anal Toxicol 2:141. doi:10.4172/2161-0525.1000141

Copyright: (C) 2012 Nasraoui-Hajaji A, et al. This is an open-access article distributed under the terms of the Creative Commons Attribution License, which permits unrestricted use, distribution, and reproduction in any medium, provided the original author and source are credited. 
continuous aeration in a nutrient solution containing $0.1 \mathrm{mM} \mathrm{KNO}$ Plants were grown in a growth chamber under controlled conditions: a $16 \mathrm{~h}$-light $\left(150 \mu \mathrm{mol} \mathrm{m} \mathrm{m}^{-2} \mathrm{~s}^{-1} \mathrm{PAR}\right) / 8 \mathrm{~h}$ dark cycle, $22^{\circ} \mathrm{C}$ (light) $/ 18^{\circ} \mathrm{C}$ (night) and $65 \%$ relatively humidity. The 7 -day-old seedlings were supplied with the nutrient solution containing $5 \mathrm{mM}$ of $\mathrm{KNO}_{3}^{-}$or $\left(\mathrm{NH}_{4}\right)_{2} \mathrm{SO}_{4}$. After 14 days of metal exposure $(0,5$ or $25 \mu \mathrm{M} \mathrm{CdCl})$, leaves were harvested and used for chemical analyses.

\section{Cadmium accumulation}

Desiccated samples were ground to a fine powder using a porcelain mortar and pestle, then digested with an acid mixture $\left(\mathrm{HNO}_{3} / \mathrm{HClO}_{4}\right.$, $\left.4 / 1 \mathrm{~cm}^{3} / \mathrm{cm}^{3}\right)$. $\mathrm{Cd}^{2+}$ concentration was determined by atomic absorption spectrophotometry (Perkin-Elmer, AAanalyst 300).

\section{Photosynthetic Pigment estimation}

Chla, Chlb and carotenoides contents were determined by the method of [15]. The absorbance of a sample was read at 645 and 663 $\mathrm{nm}$. The pigment concentrations were calculated by equations allowing a simultaneous determination of Chla and Chlb, and carotenoids.

\section{Soluble protein assays}

Soluble proteins were measured after extraction of plant tissues $(0.5$ to $1 \mathrm{~g} \mathrm{FW}$ ) at $4^{\circ} \mathrm{C}$ in $2 \mathrm{ml}$ of $\mathrm{H}_{2} \mathrm{SO}_{4}(0.3 \mathrm{mM})$ and $0.5 \%$ (w/v) Polyclar AT. The homogenate was then clarified by centrifugation for $15 \mathrm{~min}$ at 30,000 g. Proteins were determined according to Bradford [16].

\section{Estimation of lipid peroxidation}

The malondialdehyde (MDA) content of leaves was determined by using the thiobarbituric acid method, as described by Alia et al. [17]. The leaves were homogenized in 5\% (w/v) trichloroacetic acid (TCA). After centrifugation, a sample of the supernatant was added to $20 \%$ TCA containing $0.5 \%(\mathrm{w} / \mathrm{v})$ thiobarbituric acid (TBA). The mixture was incubated at $95^{\circ} \mathrm{C}$ for $30 \mathrm{~min}$. The concentration of thiobarbituric acid reacting substances was calculated using an extinction coefficient of 155 mM_1cm_1.

\section{Measurement of $\mathrm{H}_{2} \mathrm{O}_{2}$}

Content of $\mathrm{H}_{2} \mathrm{O}_{2}$ in leaves, tissues was determined based on the modified method of [18]. $\mathrm{H}_{2} \mathrm{O}_{2}$ contents were determined by colorimetric method from A508, using $\mathrm{H} 2 \mathrm{O} 2$ (30\% Sigma) (5-50 $\mu \mathrm{M})$ as a standard.

\section{Antioxidative enzymes assays}

Total CAT (EC 1.11.1.6) activity was assayed in presence of $\mathrm{H}_{2} \mathrm{O}_{2}$, according to [19], by monitoring the decline in absorbance at 240 $\mathrm{nm}$, as $\mathrm{H}_{2} \mathrm{O}_{2}$ was consumed. Enzyme activity was calculated using the extinction coefficient of $40 \mathrm{mM}^{-1} \mathrm{~cm}^{-1}$ for $\mathrm{H}_{2} \mathrm{O}_{2}$.

Total SOD (EC 1.15.1.1) activity was measured spectrophotometrically at $560 \mathrm{~nm}$ according to [20], based on the inhibition of the photochemical reduction of nitro blue tetrazolium (NBT). One unit of enzyme activity was defined as the quantity of SOD required for $50 \%$ inhibition of NBT reduction.

Total APX (EC 1.11.1.11) activity was assayed in the presence of ascorbate by following the decline in absorbance of the oxidized ascorbate at $290 \mathrm{~nm}$, according to [21]. Enzyme activity was calculated using the extinction coefficient of $2.8 \mathrm{mM}^{-1} \mathrm{~cm}^{-1}$ for ascorbate.

\section{Native polyacrylamide gel electrophoresis}

Native-PAGE was performed in slab gels containing $4 \%$ acrylamide.
At the completion of electrophoresis, bands containing SOD activity were visualized with a tetrazolium assay [22]. After incubation at $30^{\circ} \mathrm{C}$ for $30 \mathrm{~min}$ in dark, the bands were revealed in phosphate tampon (50 $\mathrm{mM}$ ) containing TEMED and riboflavine.

\section{Statistical analysis}

The results are the means \pm S.E. of at least three independent replicates. The analyses of variance were computed on statistically significant differences determined based on the appropriate F-tests. The mean differences were compared by utilizing Duncan's multiple range test.

\section{Results}

\section{Dry weight production and Cd content}

Cd effects on growth of tomato varied largely with nitrogen form. In fact, dry weight, leaf area and water tenors were negatively affected by $\mathrm{Cd}$ in $\mathrm{NO}_{3}$-fed plants. In contrary, in ammonium-fed tomato those parameters were not significantly affected by Cd (Figures 1A, 1B, 1C). Results shown in figure $1 \mathrm{D}$ demonstrated that cadmium was less accumulated in leaves of tomato grown with ammonium than with nitrate.

\section{Soluble protein content}

A significant effect on soluble protein content per DW was observed by both $\mathrm{Cd}$ and $\mathrm{N}$ regimes. A decrease in soluble protein content by $\mathrm{Cd}$ was observed when plants were grown with $\mathrm{NO}_{3}^{-}$. However, plants grown under $\mathrm{NH}_{4}^{+}$regime and treated with $\mathrm{Cd}$ exhibited a significant increase of soluble protein content (Figure 1E).

\section{Photosynthetic pigments contents}

Photosynthetic pigments measurement showed that in control plants, Chla, Chlb and carotenoides were more accumulated in nitratefed tomato. Cd reduced pigments contents in nitrate grown plants and increased them in ammonium-fed tomato (Figure 2A, 2B, 2C).

\section{Estimation of lipid peroxidation (MDA) and $\mathrm{H}_{2} \mathrm{O}_{2}$ production}

Estimation of lipid peroxidation was determined in terms of the thiobarbituric (TBA)-reactive substances, such as MDA. In control plants, MDA content was higher in ammonium-fed tomato compared to those grown with nitrate. Regardless the nitrogen form, Cd exhibited an increase in MDA level (Figure 3A). But, the MDA level was more important in nitrate-fed plants.

$\mathrm{H}_{2} \mathrm{O}_{2}$ was much higher produced in tomato leaves received ammonium as nitrogen source (Figure $3 \mathrm{~B}$ ). Cd-treated tomato content increase $\mathrm{H}_{2} \mathrm{O}_{2}$ tenor when $\mathrm{Cd}$ dose increased. Compared to ammonium-fed tomato, $\mathrm{Cd}$ induced a higher $\mathrm{H}_{2} \mathrm{O}_{2}$ production in nitrate-fed plants (Figure 3B).

\section{Antioxidant enzymes activities}

In control plants, SOD activity was higher in tomato receiving ammonium than in those grown with nitrate. Regardless nitrogen form, Cd stimulated SOD activity in tomato leaves (Figure 4A). However, in ammonium-fed plants SOD activity was more important than in nitrate-fed ones.

In parallel, native gel electrophoresis of SOD showed that $\mathrm{Cd}$ induced four isozymes (a,b,c,d) in leaves of tomato plants (Figure 4B). But, the different isozymes were highly accumulated in ammonium-fed tomato compared to nitrate fed ones. 
A

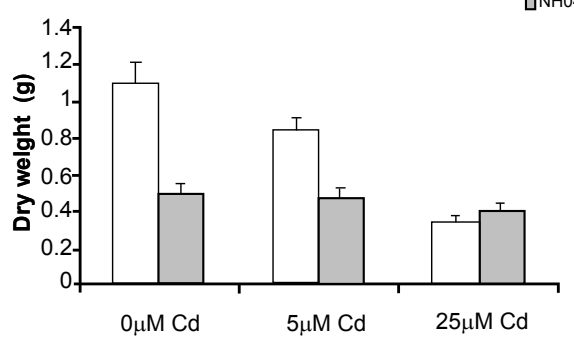

C

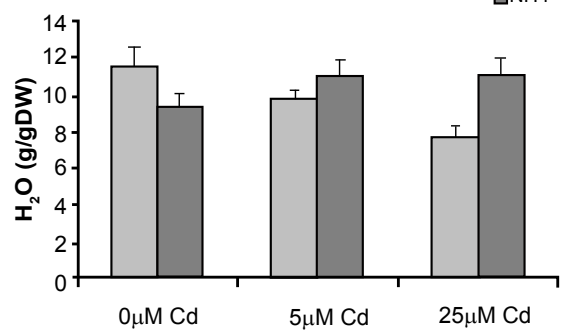

B

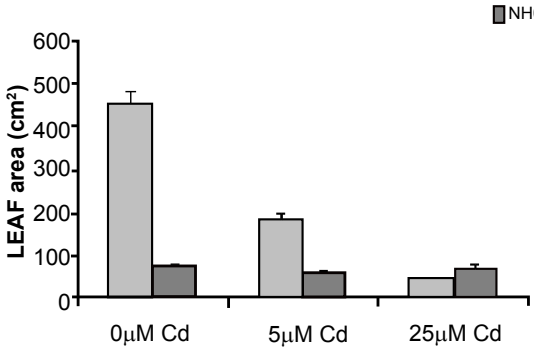

口NO3-

口NH4+

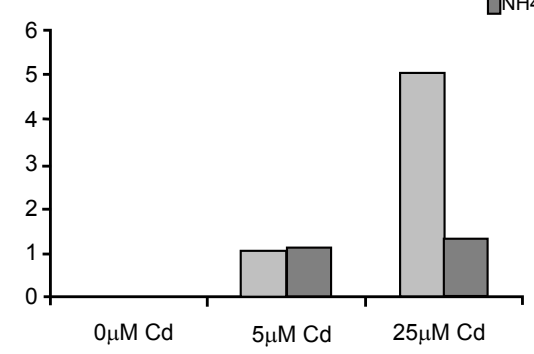

$\mathbf{E}$

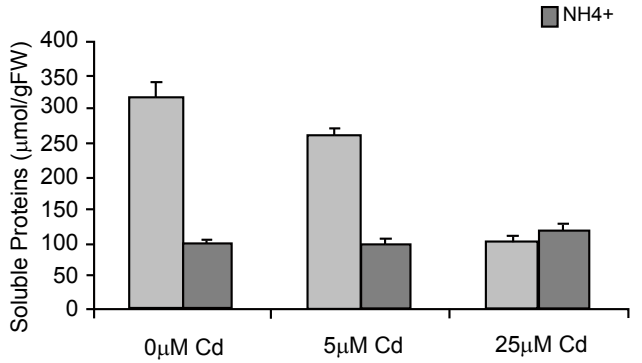

Figure 1: Dry weight (A), leaves area (B), water content (C) and cadmium content (D) in the leaves of tomato plants fed with nitrate (black symbol) or ammonium (white symbol) as nitrogen source and treated with different doses of $\mathrm{CdCl}_{2}$. Each point represents the mean $\pm \mathrm{SD}$ of triplicates from five independent experiments.

Catalase activity was more pronounced with ammonium than with nitrate (Figure 5A). Independently of nitrogen supplied, the activity of catalase was stimulated by Cd (Figure 5A). But in ammonium-fed tomato activity of this enzyme was higher than in nitrate grown plants.

A rise of the APX activity was observed in ammonium-fed tomato compared to those grown on nitrate (Figure 5B). In the tomato leaves, after cadmium exposure, APX activity increased in different leaves derived from different nitrogen regime.

\section{Discussion}

The environmental degradation, promoted mainly by anthropogenic action, has imposed strong pressure on the quality of ecosystems. The pollution of soil and water by a wide range of contaminants for both plants and animals has become a matter of great concern to researchers. In this sense, the elevated levels of heavy metals such as $\mathrm{Cd}$ in the environment are a reality today. Increasing $\mathrm{Cd}$ concentration in growth medium enhanced $\mathrm{Cd}$ accumulation in roots and shoot. However, tomato accumulated significantly higher Cd concentration in roots than in shoot [7]. Furthermore, depending on the nitrogen nutrient, potential differences among the plant so far analyzed have been observed in relation to their tolerance to $\mathrm{Cd}$. In data shown here, there is evidence suggesting that tomato plants are partially protected against $\mathrm{Cd}$ when received ammonium as nitrogen source. In fact, when Cd was added in culture medium containing ammonium as nitrogen source, tomato plants showed better growth than those control, as dry weight and Leaves area remained unchanged. More that, water, Chla, Chlb and carotenoides contents were increased in those seedlings. The lower sensitivity of photosynthetic pigments in $\mathrm{NH}_{4}^{+}$-fed tomato under $\mathrm{Cd}$ stress could be correlated to the lower content of $\mathrm{Cd}^{2+}$. This previous phenomena was explained by Chaignon 
A

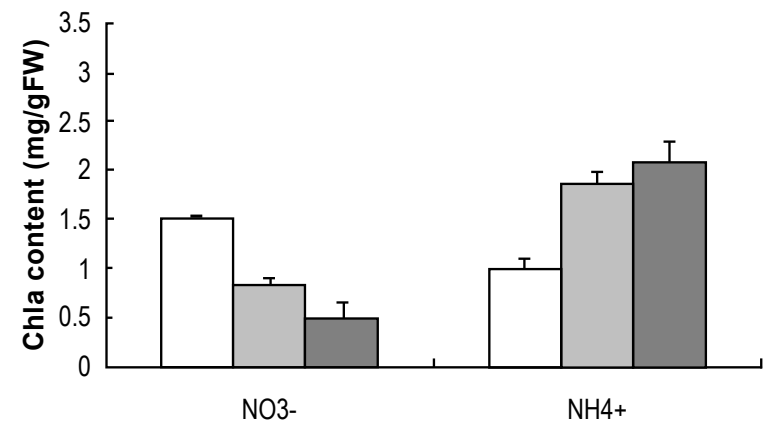

B

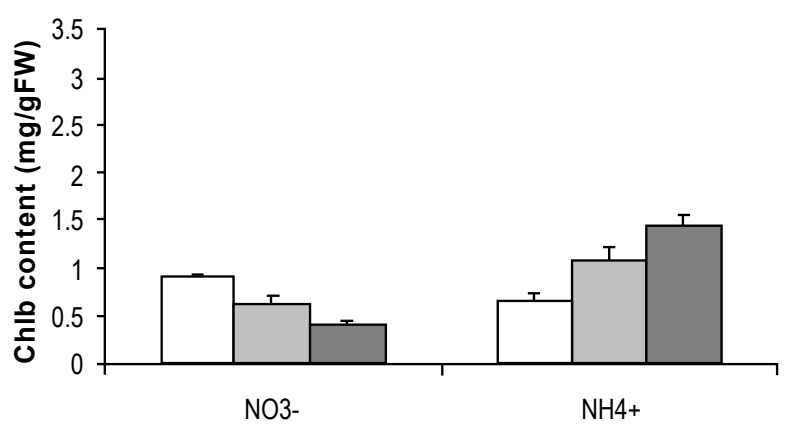

C

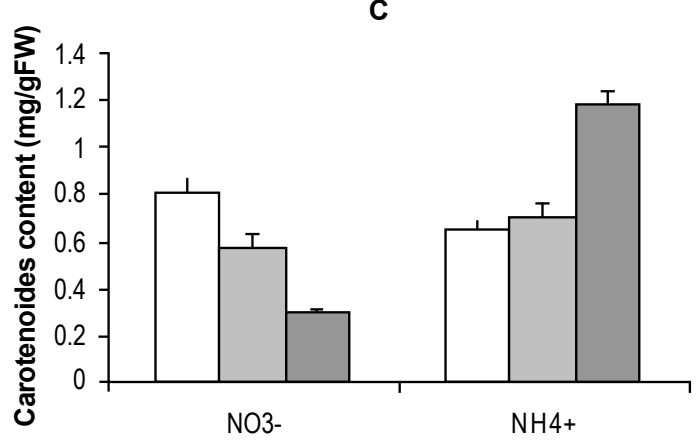

Figure 2: Tenors of $\mathrm{Chl} \mathrm{a} \mathrm{(A),} \mathrm{Chl} \mathrm{b} \mathrm{(B)} \mathrm{and} \mathrm{carotenoides}(\mathrm{C})$ in the leaves of tomato plants fed with nitrate(black symbol) or ammonium (white symbol) as nitrogen source and treated with different doses of $\mathrm{CdCl}_{2}$. Each point represents the mean \pm SD of triplicates from five independent experiments.

et al. [23], suggesting that decline in absorption and accumulation of $\mathrm{Cd}^{2+}$ were probably the result of decline of $\mathrm{pH}$ of culture medium. It should be noted that in general, metal uptake is inhibited in acidic $\mathrm{pH}$ [24].

Despite being a non-redox metal, and thus not directly producing ROS [12], Cd can interfere with antioxidant defense systems. Under stressful conditions the protective system can be overridden by a rapid production of large amounts of ROS, leading to various structural modifications in proteins [25]. These oxidative modifications are characterized by the formation of carbonyl derivatives on side chains of histidine, arginine, and proline residues [26]. Our data demonstrated that the seedling received ammonium and exposure to $\mathrm{Cd}$ caused a remarkable increase in total soluble protein content in tomato seedlings. In another study, Cargnelutti et al. [25] showed that Hg-treated cucumbers presented increased total soluble protein content. To explain this result Verma and Dubey [27] suggested that the increase in protein content is possible due to de novo synthesis of stress proteins provoked by metal exposure. These stress proteins may constitute enzymes involved in GSH and phytochelatin biosynthesis and those required for Krebs cycle, as well as antioxidants and some heat shock proteins [28].
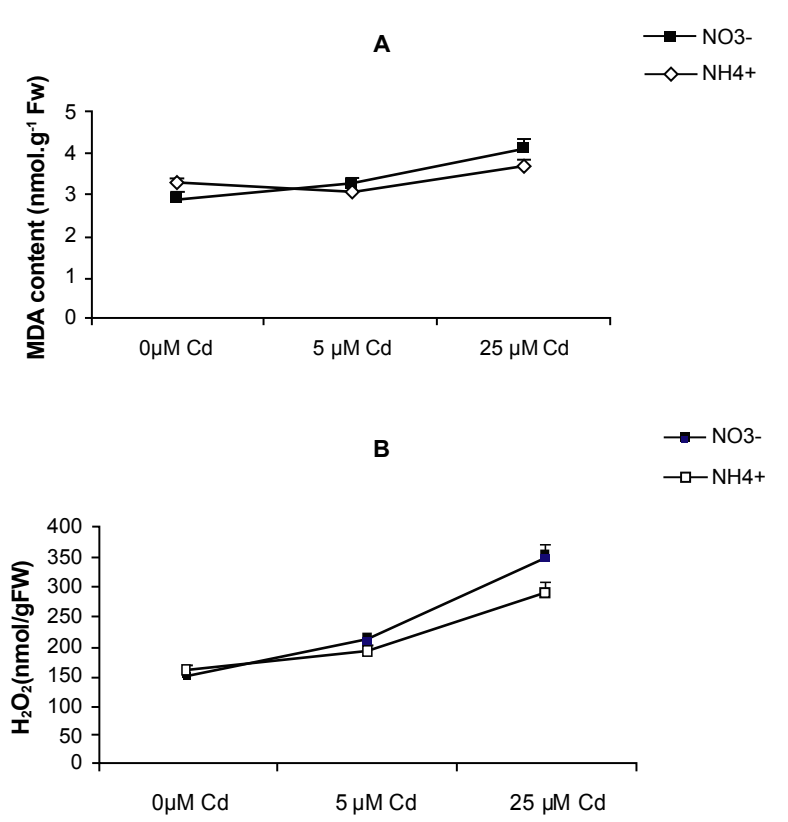

Figure 3: The level of lipid peroxidation (A) and $\mathrm{H}_{2} \mathrm{O}_{2}$ production (B), determined in terms of the TBA-reactive compounds (nmol MDA g-1 FW) in the leaves of tomato plants fed with nitrate (black symbol) or ammonium (white symbol) as nitrogen source and treated with different doses of $\mathrm{CdCl}_{2}$. Each point represents the mean \pm SD of triplicates from five independent experiments.

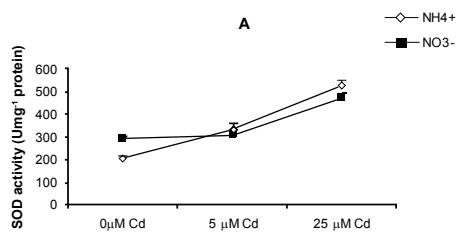

B

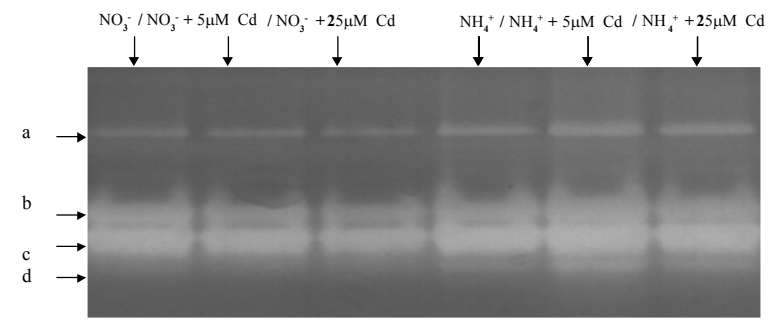

Figure 4: SOD activity $(A)$ and native activity of SOD (B) in leaves of tomato plants fed with nitrate (black symbol) or ammonium (white symbol) as nitrogen source and treated with different doses of $\mathrm{CdCl}_{2}$. Each point represents the mean \pm SD of triplicates from five independent experiments. 

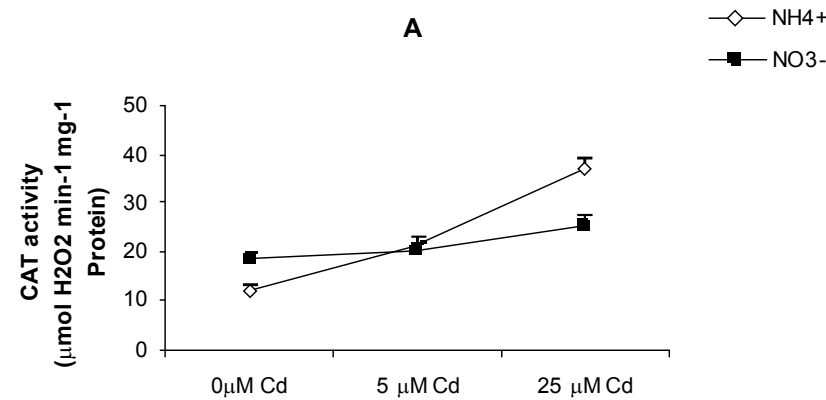

- NO3-

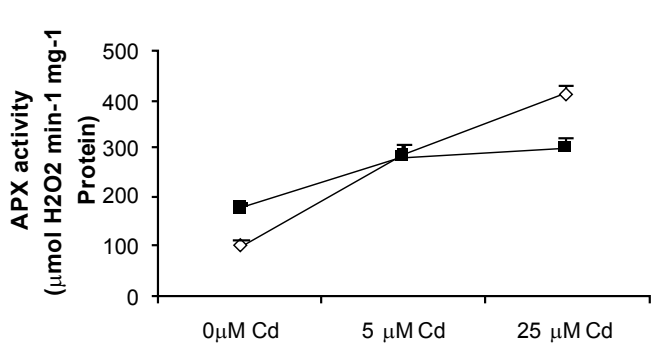

Figure 5: CAT (A) and APX activities (B) in leaves of tomato plants fed with nitrate (black symbol) or ammonium (white symbol) as nitrogen source and treated with different doses of $\mathrm{CdCl}_{2}$. Each point represents the mean $\pm \mathrm{SD}$ of triplicates from five independent experiments.

To estimate oxidative stress, the MDA tissue content had been widely used as an indicator of lipid peroxidation and, thereby, of oxidative damage in heavy-metal-exposed plants [29]. It was suggested that $\mathrm{Cd}$ may be involved in lipid peroxidation and membrane damage which was obvious from the significantly higher MDA content in leaves [30]. Our results in MDA contents showed that, regardless of nitrogen form used, presence of $\mathrm{Cd}$ induced a dramatic increase in the amount of lipid peroxidation product. But when fed with ammonium as nitrogen source, tomato accumulated lesser amount of MDA compared to in those grown with nitrate. This suggested that, $\mathrm{NH}_{4}^{+}$reduced the untimely oxidative stress situation generally generated by $\mathrm{Cd}$. The exposure of plants to Cd results in free radical production $\left(\mathrm{H}_{2} \mathrm{O}_{2}, \mathrm{OH}\right)$. This relationship between metallic stress and $\mathrm{H}_{2} \mathrm{O}_{2}$ production was well discussed in previous study [31]. To control the level of ROS and to protect the cells, plants possess antioxidant enzymes such as SOD, APX and CAT that scavenge ROS [9]. Superoxide dismutase, the first enzyme in the detoxifying process, converts superoxide radicals to $\mathrm{H}_{2} \mathrm{O}_{2}$ at a very fast rate [9]. The enhanced SOD activity observed in consistent with previous reports in which tomato and other plant species were treated with Cd $[1,30]$. Increase in SOD activity may be linked to an increase in superoxide radical formation as well as to de novo synthesis of enzyme protein $[18,26]$, which in turn may be associated with an induction of genes of SOD by superoxide-mediated signal transduction [32]. In these data, we showed that the enhancement of SOD activity by $\mathrm{Cd}$, shown in tomato derived from the two nitrogen regimes, was more pronounced in ammonium-fed tomato than in nitrate-fed seedlings. These results confirmed the fact that SOD plays an important role to alleviate oxidative stress by scavenging ROS from cell compartment. More that, it seems that $\mathrm{NH}_{4}^{+}$-fed tomato were more stressed by $\mathrm{Cd}_{2}^{+}$, since SOD activity was dependent in the intensity of oxidative stress in plant cells [30]. However, this response suggested that antioxidant system might participate in protecting tomato biochemical structures against oxidative damages and minimizing the sensitivity of the photosynthetic machinery. In previous data we showed that photosynthesis process was more protected in Cd-stressed tomato when ammonium was used as nitrogen source [7]

In another way, the increased CAT activity as found herein, which can be associated with $\mathrm{H}_{2} \mathrm{O}_{2}$ scavenging, was also observed by [1] in Coffea arabica and by [30] in Solanum lycopersicom under Cd-stress conditions. Independently of nitrogen form, this increase suggests a compensatory mechanism of defense against oxidative stress caused by this metal and can be explained by increase in its substrate to maintain the level of $\mathrm{H}_{2} \mathrm{O}_{2}$ as an adaptive mechanism of the plants [25]. Furthermore, the combined action of CAT and SOD is critical in mitigating the effects of oxidative stress, since their roles in the cell metabolism are complementary [12]. In this sense, it is interesting to note that both SOD and CAT activities increased in Cd treated tomato and that it is widely agreed that plants resist oxidative stress by increasing components of their intrinsic defensive system [12]. Another enzyme that can be activated to control and re-establish the homeostatic equilibrium of the redox status in cells is APX. In our study, the APX activity dynamics was similar to CAT and SOD in nitrate-fed tomato. Therefore, we suggest that also this enzyme participate to ROS scavenging. In fact, it was suggested that decline in $\mathrm{H}_{2} \mathrm{O}_{2}$ level in pumpkin plants is mainly due to the scavenging action of APX [33]. In another hand, APX activity, a $\mathrm{H}_{2} \mathrm{O}_{2}$-scavenger that belongs to the ascorbate-glutathione cycle, was slightly decreased by $\mathrm{Cd}$ in ammonium regime case. It seems that the reduction in APX activity may be due to GSH depletion and a subsequent reduction in the ascorbate-glutathione cycle [1]. This reduction in GSH could be caused by an increased rate of phytochelatin synthesis induced by Cd ions as suggested by [1]. Ascorbate peroxidase could be responsible for the fine modulation of ROS for signaling, and its reduced activity would lead to a deleterious imbalance in ROS production and scavenging. Furthermore, the decreased activity of APX was apparently compensated for by the increased activity of other $\mathrm{H}_{2} \mathrm{O}_{2}$-degrading enzymes like CAT [34].

Our findings added new comparative information on the metabolism response of plants under heavy metal stress. These data indicated that regardless nitrogen form, the oxidative stress was induced with cadmium. But, it was more pronounced in ammoniumfed tomato compared to nitrate-fed ones. However, $\mathrm{H}_{2} \mathrm{O}_{2}$ and MDA contents were more important in nitrate-fed tomato upon addition of Cd.

We must emphasize that cadmium provoked a more important oxidative stress situation in tomato leaves cultivated with ammonium nitrogen and therefore suggest that antioxidative response was related to the intensity of oxidative stress induced rather than to the plant sensitivity to this metal. Also, it can be assumed that ammonium regime strongly protects Solanum Lycopersicum from Cd toxicity through reducing $\mathrm{Cd}$ uptake, and lipid peroxidation and improving the ROS scavenging antioxidant enzymes activities.

\section{References}

1. Gomes-Júnior RA, Moldes CA, Delite FS, Pompeu GB, Gratão PL, et al. (2006) Antioxidant metabolism of coffee cell suspension cultures in response to cadmium. Chemosphere 65: 1330-1337.

2. Liu Y, Wang X, Zeng G, Qu D, Gu J, et al. (2007) Cadmium-induced oxidative stress and response of the ascorbate-glutathione cycle in Bechmeria nivea (L.) Gaud. Chemosphere 69: 99-107.

3. Chaffei HC, Carrayol E, Ghorbel MH, Gouia H (2009) Physiological and 
Citation: Nasraoui-Hajaji A, Gouia H, Carrayol E, Haouari-Chaffei C (2012) Ammonium Alleviates Redox State in Solanum Seedlings under Cadmium Stress Conditions. J Environ Anal Toxicol 2:141. doi:10.4172/2161-0525.1000141

biochemical effects of cadmium toxicity in enzymes involved in nitrogen and amino-acid metabolism in tomato plants. Acta Bot Gallica 156: 477-486.

4. Nasraoui HA, Ghorbel MH, Gouia H (2008) Effects of nitrate concentration on growth and nitrogen metabolism of tomato (Lycopersicon esculentum Mill.) under cadmic stress. Acta Bot Gall 155: 577-583.

5. Nasraoui HA, Chaffei HC, Ghorbel MH, Gouia H (2011) Growth and nitrate assimilation in tomato (Solanum lycopopersicum) grown with different nitrogen source and treated with cadmium Acta Bot Gall158: 3-11.

6. Maksymiec W, Wo'jcik M, Krupa Z (2007) Variation in oxidative stress and photochemical activity in Arabidopsis thaliana leaves subjected to cadmium and excess copper in the presence or absence of jasmonate and ascorbate. Chemosphere 66: 421- 427.

7. Nasraoui HA, Gharbi F, Ghorbel MH, Gouia H (2010) Cadmium stress effects on photosynthesis and PSIl efficiency in tomato grown on $\mathrm{NO}_{3}{ }^{-}$or $\mathrm{NH}_{4}^{+}$as nitrogen source. Acta Bot Gallica 157: 101-115.

8. Foyer $\mathrm{CH}$, Noctor G (2005) Redox homeostasis and antioxidant signaling: a metabolic interface between stress perception and physiological responses. Plant Cell 17: 1866-1875.

9. Gratão PL, Polle A, Lea PJ, Azevedo RA (2005) Making the life of heavy-metal stressed plants a little easier. Funct Plant Biol 32: 481-494.

10. Davies MJ (2003) Singlet oxygen-mediated damage to proteins and its consequences. Biochem Biophys Res Commun 305: 761-770.

11. López E, Arce C, Oset-Gasque MJ, Cañadas S, González MP (2006) Cadmium induces reactive oxygen species generation and lipid peroxydation in cortical neurons in culture. Free radic Biol Med 40: 940-951.

12. Benavides MP, Gallego SM, Tomaro ML (2005) Cadmium toxicity in plants. Braz J Plant Physiol 17: 21-34.

13. Sasakawa H, Yamamoto $Y$ (1978) Comparison of the uptake of nitrate and ammonium by rice seedlings: influences of light, temperature, oxygen concentration, exogenous sucrose, and metabolic inhibitors. Plant Physiol 62 : $665-669$.

14. Britto DT, Siddiqi MY, Glass AD, Kronzucker HJ (2001) Futile transmembrane $\mathrm{NH} 4$ + cycling: A cellular hypothesis to explain ammonium toxicity in plants. Proc Natl Acad Sci U S A 98: 4255- 4258.

15. Arnon DI (1949) Copper enzymes in isolated chloroplasts. Polyphenoloxidase in Beta vulgaris. Plant Physiol 24: 1-15.

16. Bradford MM (1976) A rapid and sensitive method for the quantitation of microgram quantities of protein utilizing the principle of protein-dye binding. Anal Biochem 72: 248-254.

17. Alia, Prasad KVSK, Pardha Saradhi P (1995) Effect of zinc on free radicals and proline in Brassica and Cajanus. Phytochemistry 39: 45-47.

18. Patterson BD, MacRae EA, Ferguson IB (1984) Estimation of hydrogen peroxide in plant extracts using titanium (IV). Anal Biochem 139: 487-492.

19. Chaparro-Giraldo A, Barata RM, Chabregas SM, Azevedo RA, Silva-Filho MC
(2000) Soybean leghemoglobilin targeted to potato chloroplasts influences growth and development of transgenic plants. Plant Cell Rep 19: 961-965.

20. Beyer WF, Fridovich I (1987) Assaying for superoxide dismutase activity: some large consequences of minor changes in conditions. Anal Biochem 161: 559566 .

21. Chen GX, Asada K (1989) Ascorbate peroxidase in Tea leaves: occurrence of two isozymes and the differences in their enzymatic and molecular properties. Plant Cell Physiol 30: 987-998.

22. Miller MH, Roger DB (1970) Measured Stark Widths and Shifts for Neutra Atomic Lines. Phys Rev A 1: 983-990.

23. Chaignon $V$, Bedin $F$, Hinsinger $P$ (2001) Copper bioavailability and rhizosphere $\mathrm{pH}$ changes as affected by nitrogen supply for tomato and oilseed rape cropped on an acidic and a calcareous soil. Plant Soil 243: 219-228.

24. Ahles J, Rosick E (1986) Cd uptake and influence on plasma membrane function of yeast. Toxic Environ Chem 11: 291-300.

25. Cargnelutti D, Tabaldi LA, Spanevello RM, de Oliveira Jucoski G, Battisti V et al. (2006) Mercury toxicity induces oxidative stress in growing cucumber seedlings. Chemosphere 65: 999-1006.

26. Shacter E, Williams JA, Lim M, Levine RL (1994) Differential susceptibility of plasma proteins to oxidative modification: examination by western blot immunoassay. Free Radic Biol Med 17: 429-437.

27. Verma S, Dubey RS (2003) Lead toxicity induces lipid peroxidation and alters the activities of antioxidant enzymes in growing rice plants. Plant Sci 164: 645655

28. Mishra S, Srivastava S, Tripathi RD, Kumar R, Seth CS, et al. (2006) Lead detoxification by coontail (Ceratophyllum demersum L.) involves induction of phytochelatins and antioxidant system in response to its accumulation. Chemosphere 65: 1027-1039.

29. Drazkiewicz M, Skorzynska-Polit E, Krupa Z (2007) The redox state and activity of superoxide dismutase classes in Arabidopsis thaliana under cadmium or copper stress. Chemosphere 67: 188-193.

30. Mediouni C, Ben Ammar W, Houlné G, Chaboté ME, Jemal F (2009) Cadmium and copper induction of oxidative stress and antioxidative response in tomato (Solanum lycopersicon) leaves. Plant Growth Regu 57: 89-99.

31. Haouari CC, Nasraoui HA, Carrayo E, Gouia H (2012) Redox State in Solanum Seedlings under Cadmium Stress Conditions. J Environment Analytic Toxicol 2

32. Fatima RA, Ahmad M (2005) Certain antioxidant enzymes of Allium cepa as biomarkers for the detection of toxic heavy metals in wastewater. Sci Total Environ 346: 256-273.

33. Dipierro N, Mondelli D, Paciolla C, Brunetti G, Dipierro S (2005) Changes in the ascorbate system in the response of pumpkin (Cucurbita pepo L.) roots to aluminium stress. J Plant Physiol 162: 529-536.

34. Mishra S, Srivastava S, Tripathi RD, Govindarajan R, Kuriakose SV, et al. (2006) Phytochelatin synthesis and response of antioxidants during cadmium stress in Bacopa monnieri L. Plant Physiol Biochem 44: 25-37. 